\title{
Assessment of Fuzzification Effect of AHP and TOPSIS in Site Selection of Roadside Rescue and Relief Stations
}

\author{
Ali Mansour-Khaki ${ }^{1} \mathbb{D}$, Barat Mojarradi $^{2} \mathbb{D}$, Behrouz Ghobadipour $^{3}$, Soroush Maghsoudi $^{4}$
}

Date of submission: 29 Aug. 2018, Date of acceptance: 24 Jun. 2019

\begin{abstract}
Original Article
Abstract

INTRODUCTION: In order to prevent and reduce the death and disability rates caused by road accidents, it is necessary to optimize the location of the roadside rescue and relief stations and emergency medical service. Optimal selection of the roadside rescue and relief stations is a multi-criteria decision-making (MCDM) problem and usually involves the analysis of a large number of possible options and evaluation criteria. Nowadays, various MCDM methods are used to solve location problems that may generate different results. The fuzzification of these methods has always been one of the controversial issues with many agreements and disagreements.

METHODS: In this study, a review was first performed on the weighting methods including five non-fuzzy weighting methods as row sum, column sum, arithmetic mean, geometric mean, and eigenvalues as well as two fuzzy weighting methods including: "Liu and Chen method" and "Chang Method". Then, the fuzzy and non-fuzzy MCDM methods [including analytic hierarchy process (AHP), fuzzy analytic hierarchy process (FAHP) Chang, FAHP Liu, Technique for Order of Preference by Similarity to Ideal Solution (TOPSIS), and fuzzy TOPSIS (FTOPSIS)] were employed to locate the roadside rescue and relief Stations. Due to insufficient information and all the required layers in Iran, the information of the Interstate-65 (I-65) Highway between Montgomery and Birmingham, Alabama, USA was used in the present study. Finally, the results of these methods were compared using the mean-score, Borda, and Copeland prioritization strategies.

FINDINGS: Given the importance and sensitivity of the issue, a combination of the MCDM methods was utilized to locate the roadside rescue and relief stations and the most appropriate non-fuzzy and fuzzy weighting methods were identified and the methods used were compared in terms of complexity, volume and time of computations, and the level of impact of the expert opinion.

CONCLUSION: The AHP, FAHP Liu, and Chen, FAHP Chang, and TOPSIS methods yielded more reliable results in locating the roadside rescue and relief stations; in addition, using FTOPSIS fuzzy method was more risky and is not recommended. The non-fuzzy AHP method was identified to be the most reliable method in the present study.
\end{abstract}

Keywords: Emergency Medical Service Location; Multi-Criteria Decision-Making; Prioritization Strategy; Roadside Rescue and Relief Stations

How to cite this article: Mansour-Khaki A, Mojarradi B, Ghobadipour B, Maghsoudi S. Assessment of Fuzzification Effect of AHP and TOPSIS in Site Selection of Roadside Rescue and Relief Stations. Sci J Rescue Relief 2018; 11(2): 118-28.

\section{Introduction}

$\mathrm{M}$ ulti-criteria decision making (MCDM) techniques are decision support tools designed to analyze decision-making problems, generate appropriate alternative solutions, and evaluate alternatives based on the values and preferences of the decision makers. The overall goal of these methods is to help the decision maker in selecting the best alternative from a number of applicable options in case of the

\footnotetext{
1- PhD, Faculty Member, School of Civil Engineering, Iran University of Science and Technology, Tehran, Iran

2- PhD, Faculty Member, School of Civil Engineering, Iran University of Science and Technology, Tehran, Iran

3- PhD Student, School of Civil Engineering, Iran University of Science and Technology, Tehran, Iran

4- Department of Mineral Environment, School of Mining Engineering, University of Tehran, Tehran, Iran

Correspondence to: Barat Mojarradi,Email: mojaradi@iust.ac.ir
} 
availability of multiple selection criteria and different preferences (1). MCDM methods have been widely used in various fields, including agriculture management, forestry, transportation and logistics, business and financial management, production and assembly, management and strategic planning, environmental management, military services, water management, project management, energy management, social services, etc. (2). AHP, fuzzy analytic hierarchy process (FAHP), TOPSIS, and FTOPSIS are the most common MCDM methods. Multiple MCDM methods can be used to achieve the best result. In many studies, not only several MCDM methods, but also a combination of them has been used. For example, Vinod et al. applied a combination of Fuzzy AHP and TOPSIS methods to find the best plastic recycling system (3). In addition, Nguyen et al. compared the results of the ANP Fuzzy, COPRAS-G, TOPSIS-G, SAW-G, and GRA methods to find the best approach for selecting equipment to increase market demand (4). Ghassemi and Danesh used Fuzzy AHP and TOPSIS methods to find the best desalination technology for fresh groundwater (5). Tavana et al. used the Fuzzy ANP method and the Fuzzy TOPSIS method to prioritize high-technology projects in National Aeronautics and Space Administration (NASA), USA (6). Sakthivel et al. employed the Fuzzy-AHP-TOPSIS and FuzzyAHP-VIKOR methods to select the best biodiesel blend (7). Kasirian and Yusuff used the TOPSIS, ANP, AHP, and GP preventive methods to select suppliers based on the analysis of the mutually dependent criteria (8). Wu et al. used Fuzzy Delphi, ANP, and TOPSIS to select the best supplier (9). Kabak et al. analyzed the personnel selection problem as an important management problem by ANP Fuzzy, TOPSIS Fuzzy, and ELECTR Fuzzy methods (10). Alcan et al. selected the best generation system using AHP Fuzzy and TOPSIS methods (11). Mahdavi and Niknejad applied AHP and AHP Fuzzy methods for analyzing ecotourism in Iran (12). Wang et al. used TOPSIS and AHP for irrigation planning (13). Shelton and Medina applied AHP and TOPSIS to rank transportation projects (14).

The application of the MCDM method in the analysis of emergency service optimization has been studied by a number of researchers. In particular, Rossetti and Selandari (15) applied AHP for the multi-criteria analysis of the hospital delivery system. For equipment, Singpurwalla et al. tested the AHP decision-making as a tool to distinguish between two specific health populations (16). Vahidnia et al. used the AHP method to solve the MCDM problem including hospital location selection (17). Khaki et al. employed the AHP method as well as the geographic information system (GIS) to locate the roadside rescue and relief stations (18). Daskin and Stern used a hierarchical objective set covering model for emergency medical service vehicle deployment (19). Doerner et al. suggested a heuristic solution for an extended double-coverage ambulance location problem (20). Some researchers investigated the adverse effects of fuzzification in different MCDM methods, and by applying real examples, concluded that it can be proven both mathematically and empirically that fuzzification not only does not have a positive effect on the final solutions, but also diverges them from reality (2123).

The main objective in this study is to compare the effect of fuzzification in the two most commonly used methods of AHP and TOPSIS and given the challenges posed in different studies about fuzzification, it is attempted to identify the strength and weakness of these two methods in the fuzzy and non-fuzzy modes in the location of the roadside rescue and relief stations. Moreover, the current study attempts to implement these methods for locating the rescue and relief stations and compare the results. Furthermore, to reduce the uncertainty in decision making, three ranking methods including mean score, Borda, and Copeland were exploited to combine the results of different MCDM methods and to compare the individual response of each method.

\section{Methods}

\section{Analytic Hierarchy Process (AHP)}

The AHP method was introduced by Saaty (24) and is the most widely used MCDM method currently used in various science fields to select the optimal options. AHP is a quantitative and flexible method for selecting among options based on their comparative performance using all appropriate criteria (25).

The AHP method consists of six steps as follows (26):

Step 1: Determining the decision-making problem, including the main objective, criteria, and options. 
Step 2: Making a pair-wise comparison matrix based on the Saaty scale

Step 3: Evaluating the relative importance of each criterion

Step 4: Evaluating the compatibility of the pairwise comparison matrix and the weight vector (see (21) for more details)

Step 5: Calculating the relative value of each option compared to the other options for each criterion

Step 6: Ranking options.

\section{Fuzzy Analytic Hierarchy Process (FAHP)}

The FAHP method is a combination of the AHP method and fuzzy theory (27-29), which is an effective and powerful tool for decision making problems (30). For the first time, van Laarhoven and Pedrycz applied the fuzzy logic principles to the AHP method in 1983 and called it FAHP (28). In this method, the uncertainty in the judgment of the experts can be represented by a fuzzy number. In a triangular fuzzy number (TFN), the membership function is defined by three real numbers $(1, \mathrm{~m}, \mathrm{u})$. The steps of the FAHP method are similar to those of the AHP method, with the only difference between the two methods being the different approach to weighting the criteria. The FAHP method applies the fuzzy principles for this purpose. The two common methods for determining the fuzzy weight in the AHP method are the Chang method (Fuzzy Extent Analysis) and the Liu and Chen method (Fuzzy Delphi AHP) (31).

Chang method: In 1996, Chang innovated a method for the fuzzy AHP approach, which he called "fuzzy extent analysis". In this method, the experts' judgment is expressed as TFNs. The algorithm of the Chang's method is given below (32):

Step 1: Determining the fuzzy pairwise comparison matrix of each decision maker

Step 2: Determining the sum of each row of the fuzzy pairwise comparison matrix

Step 3: Normalizing the values obtained in step 2 with fuzzy mathematical operators (these TFNs are known as the weights of each criterion relative to the other criteria).

Step 4: Calculating the degree of probability

Step 5: Estimating the priority vector.

Liu and Chen Method: Liu and Chen (2007) developed a different approach to the fuzzy AHP analysis and called it the Fuzzy Delphi AHP (FDM) method. The steps of implementation of this analysis can be summarized as follows (33):
Step 1: Building a pairwise comparison matrix for each decision maker using the relative measurement scale (24)

Step 2: Use the pairwise comparison matrices to create a fuzzy pairwise comparison matrix

Step 3: Estimating the index of agreement using the eigenvector method

Step 4: Calculating the fuzzy relative weight of each criterion and estimating the importance of the criteria

Step 5: Performing non-fuzzification based on the geometric mean method.

\section{Non-fuzzy TOPSIS method}

The TOPSIS method has been introduced by Wang and Yoon (34). This method is relatively simple and fast and comprises of the following six steps:

Step 1: Normalizing the decision matrix

Step 2: Constructing the weighted normalized decision matrix

Step 3: Identifying the positive ideal and negative ideal solutions

Step 4: Calculating the size of separation

Step 5: Calculate the relative closeness to the positive ideal and negative ideal solutions

Step 6: Ranking preference order.

\section{FTOPSIS method}

The FTOPSIS method is a combination of the TOPSIS method and fuzzy theory. In this method, as the FAHP method, the weighting is performed using the fuzzy method and the other steps are similar to those in the TOPSIS method. In the present study, TFNs and the Chang method were employed to estimate the fuzzy weights. The steps of this method are as follows:

Step 1: Determining weights by Chang method

Step 2: Ranking preference order by TOPSIS method.

\section{Findings}

\section{Scope of study}

In this study, it was attempted to use a complete set of information layers effective in locating road rescue and relief stations; however, there was no information required for any of the high-risk roads in Iran. Therefore, the Interstate-65 (I-65) Highway between Montgomery and Birmingham in Alabama State in the southeastern United States with a length of $177 \mathrm{~km}$ was selected as the study area (Figure 1). In the analyzed segment of the I-65 Highway, there are 23 intersections, 192 residential areas, 7 hospitals, and 12 gas stations. This route is a highway with a median that 
contains 2,3 , or 4 lanes at different sections on each side. This information is based on the Wikimapia database. The maximum elevation at this section of the road is $300 \mathrm{~m}$ with a maximum slope of $5 \%$ derived from the digital elevation model (DEM) of the area.

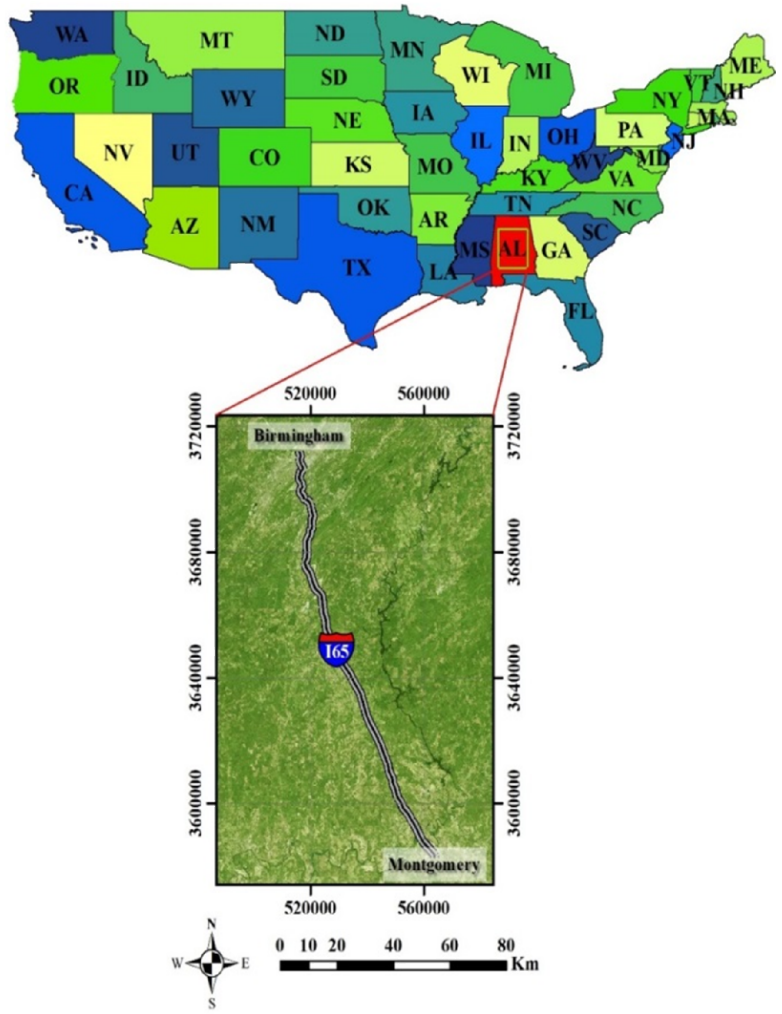

Figure 1. Interstate-65 (I-65) highway between Montgomery and Birmingham, USA

\section{Preparation of information layers}

In order to determine the required information layers as well as the criteria needed for location, the experts from the Center for Disaster Management and Medical Emergency of the country, especially from Esfahan Province, Faculty of Transportation, Iran University of Science and Technology (IUST), Tehran, Iran, and Department of Transportation Engineering, University of Isfahan, Isfahan, Iran, were used. Finally, filling in the questionnaires and taking into account the experts' opinions, and available data, 11 criteria used for analysis were selected using the MCDM methods as follows: distance from hospital (C1), arrival time (C2), potential of an accident (C3), land slope (C4), distance from river and watercourse (C5), distance from police station (C6), distance from gas station (C7), land cover (C8), distance from residential areas (C9), distance from intersection (C10), and distance from the highway (C11).

In the present study, the information layers were obtained in ArcGIS software environment. The geographical coordinates of the hospitals around the route were used to generate the distance from the hospital layer. For this purpose, first the distance from the hospital layer was produced and then classified based on the effective distance to the nearest hospital. The layers of distance from the police station, distance from intersection, distance from residential areas, distance from gas station, and distance from highway were created in a similar way. Moreover, the 2001 to 2011 accident data associated with the adjacent areas of the I-65 Highway were utilized to generate the accident potential layer. These data were obtained from the Fatality Analysis Reporting System (FARS) (35). The density of the number of accidents and the surrounding casualties was determined to determine the potential of accident at any point. The combination of the accident data and annual average daily traffic (AADT) was used to determine the reaching time at each point. It was not possible to provide these information layers for an appropriate road in Iran, so the I-65 highway in the United States was used. The slope layer was generated using the digital elevation model (DEM) (ester satellite with a resolution of $30 \mathrm{~m}$ pixels) of the area using ENVI software. The layer of distance from river and watercourse was also modeled using the DEM with the help of ArcHydro tool. Initially, the basins were extracted and the path of the rivers and seasonal floods were identified; then the distance layer of these paths was prepared and classified. To generate the land cover layer, the data of the ETM satellite obtained from the American National Land Cover Database (NLCD), 2001 were used (36) and the final map was completed in ENVI software (Figure 2). The land use information layer has not been well prepared in Iran and there is not a suitable layer available to researchers in this regard as well. The I-65 interstate highway map and all surrounding roads are based on the National Atlas of the United States (37). 


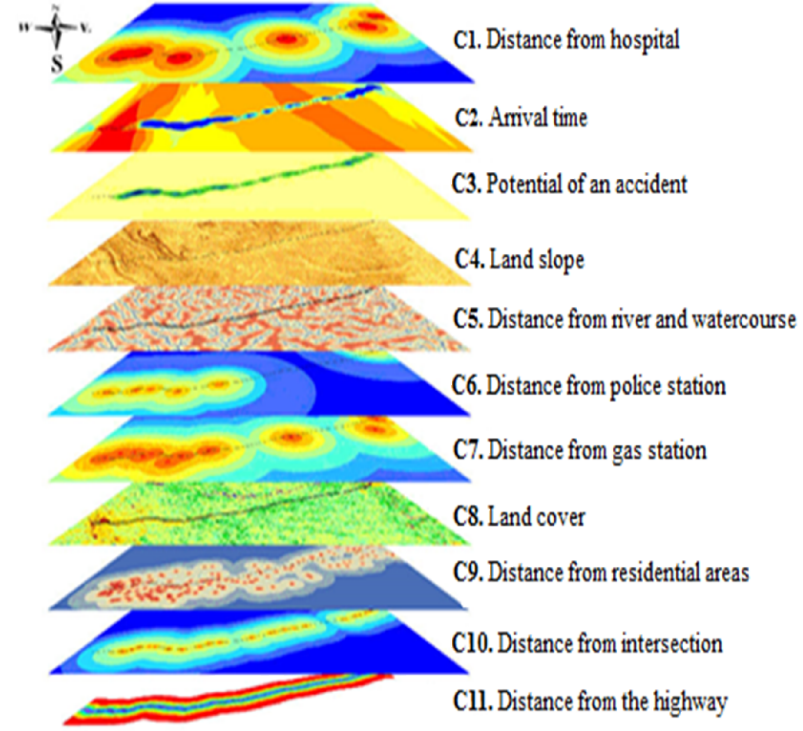

Figure 2. Classified layers

\section{Determining the weight of the criteria and choosing the options}

Determining the weight of the criteria: To determine the weight of the criteria, 16 experts were asked to evaluate the relative importance of the criteria selected based on the Saaty rating scale (Table 1). Then, the weight of the criteria was calculated with five weighting methods including row sum (38), column sum (38), arithmetic mean (39), geometric mean (39), and eigenvalue as well as the two fuzzy Liu and Chen and fuzzy Chang weighting methods. A 9-point scale questionnaire was employed to determine the weight of the criteria and it was found that the results obtained from the questionnaire were the same for all non-fuzzy weighting methods used (Table 2).

\section{Selection of options}

For location, the desired options needed to be selected first. For this purpose, after integrating the information layers using the simple additive weighting (SAW) method in ArcMap software, 16 points with the highest potential for constructing rescue and relief stations along the route were selected. Then the relative value of each pixel in each layer was extracted and used as the decision matrix in the MCDM methods (Table 3).

\section{Prioritization of options}

Prioritization by AHP method: The criteria weight vector and the relative value of options in each criterion (decision matrix) were calculated in the previous section. Multiplying the weight vector by the decision matrix yielded a $1 \times 16$ vector. This vector indicates the preference of options to determine the roadside rescue and relief stations position. The final values and ranks of the options in the AHP method are presented in Table 4, and the options with the highest potential for selection are identified as the rescue and relief stations.

\section{Prioritization by FAHP method}

In the FAHP method, the weights of the criteria are calculated using the Chang method and the Liu and Chen method.

These methods are based on fuzzy numbers. In this study, TFNs were used to determine the weight of each criterion given the main goal. The FAHP method in the present study was implemented in two ways, which are discussed in the following.

Table 1. Experts' estimates of the importance of criteria

\begin{tabular}{clllllllllllllllll}
\hline Criteria & \multicolumn{10}{c}{ Experts' judgment } \\
\hline Hospital & 5 & 9 & 9 & 7 & 9 & 9 & 7 & 9 & 9 & 5 & 9 & 5 & 5 & 9 & 9 & 3 \\
Arrival time & 9 & 9 & 9 & 9 & 9 & 9 & 9 & 9 & 9 & 9 & 9 & 9 & 9 & 9 & 9 & 9 \\
Potential & 9 & 7 & 7 & 7 & 7 & 9 & 9 & 5 & 5 & 9 & 7 & 9 & 9 & 9 & 7 & 9 \\
Slope & 7 & 3 & 3 & 5 & 1 & 3 & 5 & 5 & 7 & 3 & 3 & 3 & 3 & 3 & 3 & 3 \\
River and watercourse & 7 & 5 & 5 & 7 & 3 & 5 & 7 & 5 & 7 & 9 & 3 & 5 & 7 & 5 & 5 & 3 \\
Police station & 9 & 9 & 9 & 9 & 7 & 9 & 5 & 3 & 5 & 7 & 7 & 5 & 7 & 5 & 5 & 3 \\
Gas station & 7 & 5 & 5 & 7 & 7 & 9 & 9 & 7 & 3 & 5 & 7 & 7 & 5 & 3 & 3 & 3 \\
Land cover & 5 & 5 & 5 & 7 & 5 & 7 & 5 & 3 & 5 & 3 & 3 & 5 & 7 & 7 & 3 & 9 \\
Residential Areas & 9 & 9 & 9 & 9 & 9 & 9 & 7 & 7 & 9 & 9 & 7 & 7 & 7 & 7 & 5 & 9 \\
Intersection & 9 & 9 & 9 & 9 & 9 & 9 & 7 & 9 & 9 & 9 & 7 & 5 & 9 & 5 & 5 & 5 \\
Highway & 3 & 5 & 3 & 1 & 3 & 5 & 3 & 3 & 3 & 3 & 1 & 3 & 5 & 3 & 3 & 5 \\
\hline
\end{tabular}


Table 2. Weighting of criteria by five conventional methods and two fuzzy methods

\begin{tabular}{c|cc|c|cccc} 
Criteria & \multicolumn{7}{c}{ Weighting methods } \\
\cline { 2 - 8 } & FUZZY Chang & Fuzzy Liu & Eigen vector & Geo-mean & Arithmetic average & Column sum & Row sum \\
\hline C1 & 0.0976 & 0.0767 & 0.1047 & 0.1047 & 0.1047 & 0.1047 & 0.1047 \\
C2 & 0.1035 & 0.1106 & 0.1340 & 0.1340 & 0.1340 & 0.1340 & 0.1340 \\
C3 & 0.0988 & 0.1005 & 0.1340 & 0.1340 & 0.1133 & 0.1133 & 0.1133 \\
C4 & 0.0743 & 0.0731 & 0.0510 & 0.0510 & 0.0510 & 0.0510 & 0.0510 \\
C5 & 0.0872 & 0.0982 & 0.0780 & 0.0780 & 0.0780 & 0.0780 & 0.0780 \\
C6 & 0.0929 & 0.1022 & 0.0913 & 0.0913 & 0.0913 & 0.0913 & 0.0913 \\
C7 & 0.0900 & 0.0987 & 0.0800 & 0.0800 & 0.0800 & 0.0800 & 0.0800 \\
C8 & 0.08993 & 0.0710 & 0.0739 & 0.0739 & 0.0739 & 0.0739 & 0.0739 \\
C9 & 0.1002 & 0.0939 & 0.1175 & 0.1175 & 0.1175 & 0.1175 & 0.1175 \\
C10 & 0.0989 & 0.0986 & 0.1121 & 0.1121 & 0.1121 & 0.1121 & 0.1121 \\
C11 & 0.0674 & 0.0765 & 0.0442 & 0.0442 & 0.0442 & 0.0442 & 0.0442 \\
\hline
\end{tabular}

Table 3. Relative value of each pixel in each criterion layer

\begin{tabular}{cccccccccccc|c|c|} 
Option & \multicolumn{10}{c|}{ Layer value } \\
\cline { 2 - 12 } & C1 & C2 & C3 & C4 & C5 & C6 & C7 & C8 & C9 & C10 & C11 \\
\hline 1 & 6 & 10 & 5 & 4 & 8 & 3 & 6 & 8 & 9 & 4 & 6 \\
2 & 5 & 10 & 4 & 4 & 7 & 5 & 4 & 8 & 9 & 4 & 6 \\
3 & 6 & 10 & 6 & 5 & 4 & 7 & 3 & 8 & 3 & 6 & 9 \\
4 & 5 & 10 & 5 & 4 & 8 & 7 & 3 & 8 & 3 & 6 & 9 \\
5 & 2 & 10 & 6 & 4 & 8 & 6 & 5 & 8 & 9 & 2 & 9 \\
6 & 3 & 10 & 4 & 3 & 8 & 5 & 6 & 8 & 9 & 3 & 8 \\
7 & 6 & 8 & 4 & 4 & 8 & 8 & 4 & 8 & 5 & 5 & 7 \\
8 & 3 & 10 & 5 & 4 & 7 & 7 & 7 & 8 & 5 & 3 & 9 \\
9 & 3 & 10 & 5 & 2 & 6 & 7 & 5 & 8 & 5 & 4 & 8 \\
10 & 5 & 10 & 6 & 4 & 8 & 3 & 7 & 8 & 7 & 3 & 8 \\
11 & 4 & 10 & 3 & 4 & 7 & 4 & 9 & 9 & 9 & 3 & 9 \\
12 & 2 & 10 & 5 & 6 & 6 & 3 & 7 & 9 & 9 & 3 & 9 \\
13 & 3 & 10 & 6 & 4 & 6 & 3 & 7 & 8 & 9 & 2 & 9 \\
14 & 2 & 10 & 9 & 4 & 7 & 2 & 7 & 8 & 7 & 2 & 7 \\
15 & 3 & 10 & 7 & 4 & 8 & 7 & 5 & 8 & 2 & 4 & 8 \\
16 & 4 & 10 & 4 & 4 & 7 & 7 & 4 & 8 & 3 & 5 & 9 \\
\hline
\end{tabular}

Chang method: In order to determine the criteria fuzzy weight, the Chang method was employed to determine the degree of probability and the estimated priority vector of the fuzzy pairwise comparison matrix (Table 4). The final step of the Chang method is the same as the common AHP method. The results and ranking of options by the FAHP method are presented in Table 5.

Liu and Chen method: In this method, like the Chang method, TFNs are used to indicate the weight of each criterion. To do this, the relative fuzzy weight was initially calculated and the final weight of each criterion was determined by nonfuzzification based on the geometric mean method (Table 4).
Table 4. Analytical hierarchy process (AHP) values and their rank for rescue and relief stations location

\begin{tabular}{|ccccc}
\hline \multicolumn{2}{|c}{ AHP results } & \multicolumn{2}{c}{ AHP prioritization } \\
\hline Option & Value & Option & Value \\
\hline 1 & 0.0672 & 1 & 0.0672 \\
2 & 0.0638 & 3 & 0.0662 \\
3 & 0.0662 & 7 & 0.0654 \\
4 & 0.0651 & 4 & 0.0651 \\
5 & 0.0614 & 10 & 0.0642 \\
6 & 0.0609 & 11 & 0.0639 \\
7 & 0.0654 & 2 & 0.0638 \\
8 & 0.0612 & 5 & 0.0614 \\
9 & 0.0587 & 8 & 0.0612 \\
10 & 0.0642 & 12 & 0.0612 \\
11 & 0.0639 & 6 & 0.0609 \\
12 & 0.0612 & 15 & 0.0609 \\
13 & 0.0602 & 16 & 0.0604 \\
14 & 0.0592 & 13 & 0.0602 \\
15 & 0.0609 & 14 & 0.0592 \\
16 & 0.0604 & 9 & 0.0587 \\
\hline
\end{tabular}

The final step of the FAHP method using the Liu and Chen weighting method is similar to the common AHP method. The FAHP results and rankings of options by the Liu and Chen method are presented in Table 6.

\section{Prioritization by TOPSIS method}

The data required for this decision-making in the TOPSIS method used to rank the proposed rescue and relief sites is presented in the decision matrix (Table 5). After calculating the weight of the criteria (Table 4), the weighted normalized decision matrix was calculated and the positive ideal and negative ideal solutions were specified as demonstrated in Table 7. 
Table 5. Results and ranking of options by fuzzy analytical hierarchy process (FAHP) method with Chang weighting method

\begin{tabular}{|c|c|c|c|}
\hline \multicolumn{2}{|c|}{ FAHP (Chang) results } & FAHP (Chang) & prioritization \\
\hline Option & Value & Option & Value \\
\hline 1 & 0.0661 & 1 & 0.0661 \\
2 & 0.0628 & 3 & 0.0659 \\
3 & 0.0659 & 7 & 0.0655 \\
4 & 0.0659 & 4 & 0.0650 \\
5 & 0.0615 & 11 & 0.0646 \\
6 & 0.0607 & 10 & 0.0642 \\
7 & 0.0655 & 2 & 0.0628 \\
8 & 0.0621 & 12 & 0.0622 \\
9 & 0.0581 & 8 & 0.0621 \\
10 & 0.0642 & 5 & 0.0615 \\
11 & 0.0646 & 15 & 0.0614 \\
12 & 0.0622 & 16 & 0.0608 \\
13 & 0.0603 & 6 & 0.0607 \\
14 & 0.0589 & 13 & 0.0603 \\
15 & 0.0614 & 14 & 0.0589 \\
16 & 0.0608 & 9 & 0.0581 \\
\hline
\end{tabular}

The distance from the positive ideal and negative ideal solutions was calculated for each option and ultimately, given the proximity to the ideal solution value, the proposed options were prioritized for rescue and relief stations (Table 8).

\section{Prioritization by FTOPSIS method}

The steps of the FTOPSIS method are similar to those of the TOPSIS method, but in the FTOPSIS method the weight of the criteria is calculated using fuzzy numbers. For each criterion, the minimum, average, and maximum of the expert judgment is used to generate the fuzzy number and its membership function is defined by $(1, \mathrm{~m}$, u) respectively (Table 9). After converting the decision matrix to the fuzzy decision matrix, the final score and ranking of options are determined. The results obtained by the FTOPSIS method are shown in Table 10.

\section{Integration of prioritization methods and strategies} Prioritization of options by AHP, Liu and Chen FAHP, Chang FAHP, TOPSIS, and FTOPSIS methods is summarized in Table 11. Comparing these methods, it can be observed that option 1 has been selected as the best option in all methods.

Table 6. Results and ranking of options by fuzzy analytical hierarchy process (FAHP) method with Liu and Chen weighting method

\begin{tabular}{cccc}
\multicolumn{2}{c}{ FAHP (Liu \& Chen) } & \multicolumn{2}{c}{$\begin{array}{c}\text { FAHP (Liu \& Chen) } \\
\text { prioritization }\end{array}$} \\
\hline Option & Value & Option & Value \\
\hline 1 & 0.0675 & 1 & 0.0675 \\
2 & 0.0641 & 3 & 0.0656 \\
3 & 0.0656 & 7 & 0.0648 \\
4 & 0.0647 & 4 & 0.0647 \\
5 & 0.0615 & 10 & 0.0644 \\
6 & 0.0612 & 11 & 0.0641 \\
7 & 0.0648 & 2 & 0.0641 \\
8 & 0.0609 & 12 & 0.0616 \\
9 & 0.0587 & 5 & 0.0615 \\
10 & 0.0644 & 6 & 0.0612 \\
11 & 0.0641 & 8 & 0.0609 \\
12 & 0.0616 & 13 & 0.0606 \\
13 & 0.0606 & 15 & 0.0605 \\
14 & 0.0598 & 16 & 0.0599 \\
15 & 0.0605 & 14 & 0.0598 \\
16 & 0.0599 & 9 & 0.0597 \\
\hline
\end{tabular}

Table 7. Weighted normalized decision matrix and maximum and minimum values

\begin{tabular}{cccc|ccc|ccccc}
\hline & $\mathbf{C 1}$ & $\mathbf{C 2}$ & $\mathbf{C 3}$ & $\mathbf{C 4}$ & $\mathbf{C 5}$ & $\mathbf{C 6}$ & $\mathbf{C 7}$ & $\mathbf{C 8}$ & $\mathbf{C 9}$ & $\mathbf{C 1 0}$ & $\mathbf{C 1 1}$ \\
1 & 0.038 & 0.034 & 0.026 & 0.013 & 0.022 & 0.012 & 0.021 & 0.018 & 0.038 & 0.029 & 0.008 \\
2 & 0.032 & 0.034 & 0.021 & 0.013 & 0.019 & 0.020 & 0.014 & 0.018 & 0.038 & 0.029 & 0.008 \\
3 & 0.038 & 0.034 & 0.031 & 0.016 & 0.011 & 0.029 & 0.010 & 0.018 & 0.013 & 0.043 & 0.012 \\
4 & 0.032 & 0.034 & 0.026 & 0.013 & 0.022 & 0.029 & 0.010 & 0.018 & 0.013 & 0.043 & 0.012 \\
5 & 0.013 & 0.034 & 0.031 & 0.013 & 0.022 & 0.025 & 0.017 & 0.018 & 0.038 & 0.014 & 0.012 \\
6 & 0.019 & 0.034 & 0.021 & 0.009 & 0.022 & 0.020 & 0.021 & 0.018 & 0.038 & 0.022 & 0.011 \\
7 & 0.038 & 0.027 & 0.021 & 0.013 & 0.022 & 0.033 & 0.014 & 0.018 & 0.021 & 0.036 & 0.009 \\
8 & 0.019 & 0.034 & 0.026 & 0.013 & 0.019 & 0.029 & 0.024 & 0.018 & 0.021 & 0.022 & 0.012 \\
9 & 0.019 & 0.034 & 0.026 & 0.006 & 0.016 & 0.029 & 0.017 & 0.018 & 0.021 & 0.029 & 0.011 \\
10 & 0.032 & 0.034 & 0.031 & 0.013 & 0.022 & 0.012 & 0.024 & 0.018 & 0.030 & 0.022 & 0.011 \\
11 & 0.025 & 0.034 & 0.016 & 0.013 & 0.019 & 0.016 & 0.031 & 0.021 & 0.038 & 0.022 & 0.012 \\
12 & 0.013 & 0.034 & 0.026 & 0.019 & 0.016 & 0.012 & 0.024 & 0.021 & 0.038 & 0.022 & 0.012 \\
13 & 0.019 & 0.034 & 0.031 & 0.013 & 0.016 & 0.012 & 0.024 & 0.018 & 0.038 & 0.014 & 0.012 \\
14 & 0.013 & 0.034 & 0.047 & 0.013 & 0.019 & 0.008 & 0.024 & 0.018 & 0.030 & 0.014 & 0.009 \\
15 & 0.019 & 0.034 & 0.037 & 0.013 & 0.022 & 0.029 & 0.017 & 0.018 & 0.009 & 0.029 & 0.011 \\
16 & 0.025 & 0.034 & 0.021 & 0.013 & 0.019 & 0.029 & 0.014 & 0.018 & 0.013 & 0.036 & 0.012 \\
Ideal+ & 0.038 & 0.034 & 0.047 & 0.019 & 0.022 & 0.033 & 0.031 & 0.021 & 0.038 & 0.043 & 0.012 \\
Ideal- & 0.013 & 0.027 & 0.016 & 0.006 & 0.011 & 0.008 & 0.010 & 0.018 & 0.009 & 0.014 & 0.008 \\
\hline
\end{tabular}


Table 8. Results and ranking of options by Technique for Order of Preference by Similarity to Ideal Solution (TOPSIS) method

\begin{tabular}{|c|c|c|c|}
\hline \multicolumn{2}{|c|}{ TOPSIS results } & \multicolumn{2}{c|}{ TOPSIS prioritization } \\
\hline Option & Value & Option & Value \\
\hline 1 & 0.0661 & 1 & 0.0661 \\
2 & 0.0628 & 3 & 0.0659 \\
3 & 0.0659 & 7 & 0.0655 \\
4 & 0.0650 & 4 & 0.0650 \\
5 & 0.0615 & 11 & 0.0646 \\
6 & 0.0607 & 10 & 0.0642 \\
7 & 0.0655 & 2 & 0.0628 \\
8 & 0.0621 & 12 & 0.0622 \\
9 & 0.0581 & 8 & 0.0621 \\
10 & 0.0642 & 5 & 0.0615 \\
11 & 0.0646 & 15 & 0.0614 \\
12 & 0.0622 & 16 & 0.0608 \\
13 & 0.0603 & 6 & 0.0607 \\
14 & 0.0589 & 13 & 0.0603 \\
15 & 0.0614 & 14 & 0.0589 \\
16 & 0.0608 & 9 & 0.0581 \\
\hline
\end{tabular}

The nature of the problems analyzed using the MCDM methods is such that they may not have definite solutions, thus the results of different methods for a single prioritization may differ (Table 11).

Table 9. Fuzzy normal weights of the criteria used in the fuzzy Technique for Order of Preference by

Similarity to Ideal Solution (FTOPSIS)

\begin{tabular}{|cccc}
\multirow{2}{*}{ Criteria } & \multicolumn{3}{|c}{ evaluation process } \\
\cline { 2 - 4 } & $\mathbf{l}$ & $\mathbf{~ m}$ & $\mathbf{u}$ \\
C1 & 0.0492 & 0.1065 & 0.1579 \\
C2 & 0.1084 & 0.1301 & 0.1579 \\
C3 & 0.0704 & 0.1117 & 0.1475 \\
C4 & 0.0145 & 0.0535 & 0.0986 \\
C5 & 0.0435 & 0.0783 & 0.1268 \\
C6 & 0.0462 & 0.0917 & 0.1233 \\
C7 & 0.0423 & 0.0817 & 0.1233 \\
C8 & 0.0423 & 0.0753 & 0.1475 \\
C9 & 0.0877 & 0.1144 & 0.1475 \\
C10 & 0.0769 & 0.1101 & 0.1385 \\
C11 & 0.0130 & 0.0467 & 0.0820 \\
\hline
\end{tabular}

In such cases, several decision-making methods can be used, and in case of a discrepancy among these methods, the final decision-making strategies are applied. Therefore, the results can be judged more confidently. In such conditions, different integration methods are employed, including the grade averaging method, the Borda method, and the Copeland method.
Table 10. Final score and ranking of options by the fuzzy Technique for Order of Preference by Similarity to Ideal Solution (FTOPSIS) method

\begin{tabular}{|cccc|}
\hline \multicolumn{2}{|c}{ FTOPSIS results } & \multicolumn{2}{c|}{ FTOPSIS prioritization } \\
\hline Option & Value & Option & Value \\
\hline 1 & 0.0723 & 1 & 0.0723 \\
2 & 0.0665 & 10 & 0.0686 \\
3 & 0.0665 & 7 & 0.0672 \\
4 & 0.0672 & 4 & 0.0672 \\
5 & 0.0609 & 3 & 0.0665 \\
6 & 0.0603 & 2 & 0.0665 \\
7 & 0.0672 & 11 & 0.0656 \\
8 & 0.0615 & 8 & 0.0615 \\
9 & 0.0539 & 5 & 0.0609 \\
10 & 0.0686 & 6 & 0.0603 \\
11 & 0.0656 & 12 & 0.0589 \\
12 & 0.0589 & 15 & 0.0589 \\
13 & 0.0582 & 16 & 0.0587 \\
14 & 0.0547 & 13 & 0.0582 \\
15 & 0.0589 & 14 & 0.0547 \\
16 & 0.0587 & 9 & 0.0539 \\
\hline
\end{tabular}

In the grade averaging method, the numerical average of the rankings obtained from different methods is calculated for each option and eventually, based on which the options are ranked. An option with a smaller numerical average is clearly evaluated as the best option. Table 12 indicates the final ranking using the grade averaging method.

Table 11. Final result and ranking of options by analytical hierarchy process (AHP), Liu and Chen fuzzy AHP (FAHP), Chang FAHP, Technique for Order of Preference by Similarity to Ideal Solution (FTOPSIS), and fuzzy TOPSIS (FTOPSIS) methods

\begin{tabular}{cccccc|}
\hline & \multicolumn{5}{c|}{ Prioritization } \\
\cline { 2 - 6 } & AHP & $\begin{array}{c}\text { FAHP Liu } \\
\text { \&Chen }\end{array}$ & $\begin{array}{c}\text { FAHP } \\
\text { Chang }\end{array}$ & $\begin{array}{c}\text { TOPS } \\
\text { IS }\end{array}$ & $\begin{array}{c}\text { FTOP } \\
\text { SIS }\end{array}$ \\
\hline 1 & 1 & 1 & 1 & 1 & 1 \\
2 & 3 & 3 & 3 & 3 & 10 \\
3 & 7 & 7 & 7 & 7 & 7 \\
4 & 4 & 4 & 4 & 2 & 4 \\
5 & 10 & 10 & 11 & 4 & 3 \\
6 & 11 & 11 & 10 & 10 & 2 \\
7 & 2 & 2 & 2 & 11 & 11 \\
8 & 5 & 12 & 12 & 5 & 8 \\
9 & 12 & 5 & 8 & 14 & 5 \\
10 & 8 & 6 & 5 & 6 & 6 \\
11 & 15 & 8 & 15 & 13 & 12 \\
12 & 6 & 13 & 16 & 15 & 15 \\
13 & 16 & 15 & 6 & 12 & 16 \\
14 & 13 & 16 & 13 & 8 & 13 \\
15 & 14 & 14 & 14 & 16 & 14 \\
16 & 9 & 9 & 9 & 9 & 9 \\
\hline
\end{tabular}


In the Borda method, a pairwise comparison matrix is produced and the ranking of options in different methods is compared. If the number of times that an option has a better rank than the other option in different methods is greater, then it will be shown with 1 , otherwise it will be shown with zero. The pairwise comparison matrix is then completed, with the sum of each row representing the number of times that one option is preferred to the other and the options are ranked based on these values (Table 12).

The Copeland method is a modified form of the Borda method, but it also considers the number of times that one option has a worse rank than the other in different methods. Therefore, the ranking is performed using the difference between the sum of rows and the sum of columns for each option (Table 12).

Table 12. Results of the grade averaging, Borda, and Copeland methods for ranking the rescue and relief stations options

\begin{tabular}{|c|c|c|c|}
\hline Option & Grade averaging & Borda & Copeland \\
\hline 1 & 1 & 1 & 1 \\
2 & 3 & 3 & 3 \\
3 & 7 & 7 & 7 \\
4 & 4 & 4 & 4 \\
5 & 10 & 10 & 10 \\
6 & 2 & 11 & 11 \\
7 & 11 & 2 & 2 \\
8 & 5 & 5 & 5 \\
9 & 12 & 12 & 12 \\
10 & 8 & 8 & 8 \\
11 & 6 & 6 & 6 \\
12 & 15 & 15 & 15 \\
13 & 13 & 16 & 16 \\
14 & 16 & 13 & 13 \\
15 & 14 & 14 & 14 \\
16 & 9 & 9 & 9 \\
\hline
\end{tabular}

Based on Table 11, all methods have preferred option 1 and slightly differ in preferences 2 to 7 , however in preference 8 on, this difference is sharpened, which can be due to the following:

- According to Table 3, the values of the first option are very different from those of the other options.
- According to tables 11 and 12 all methods have correctly selected the first 7 options. The values of these options have little difference in comparison to option 1.

- The values of options 8 to 16 are slightly different. Hence, all methods have yielded different results.

The results of the AHP and FAHP methods are very similar (Table 11), suggesting that fuzzyization has not significantly affected the results while increasing the computational time and volume. Saaty also noted in a study that "fuzzification of numerical judgments does not significantly improve the multi-criteria decisionmaking" (21). In the present study, 16 options were selected by the SAW method from the 25 million pixels forming the options. Since the FAHP and AHP methods are not significantly different from each other and given the higher computation volume in the FTOPSIS method, methods such as AHP can be used for initial location rather than the simple SAW method, in addition to taking the advantage of the reduced computation time in this method.

MCDM methods have been compared in Table 13 in terms of complexity, volume, and time of computations, and the effect of the experts' opinion. This table can be used to choose the appropriate method to make decisions.

\section{Discussion and Conclusion}

Choosing the proper method is very important in problems in which several criteria are involved in decision-making. For example, as illustrated in Table 11, when the FAHP methods are used, if the goal is to select five options, the Liu and Chen FAHP method and Chang FAHP method choose options 10 and 11 as the last option, respectively. Choosing between options 10 or 11 may shift the location of the rescue and relief stations station a few kilometers and even change the annual number of casualties. Evaluation of the results obtained by applying the MCDM methods in locating the rescue and relief stations in the present study led to the following findings:

Table 13. Comparison of the methods used in terms of complexity, volume and time of computations, and the effect of the experts' opinion

\begin{tabular}{llcccc} 
Complexity of method & AHP & TOPSIS & FAHP Liu \& Chen & FAHP Chang & FTOPSIS \\
Volume of computations & AHP & TOPSIS & FAHP Liu \& Chen & FAHP Chang & FTOPSIS \\
The effect of the experts & AHP & TOPSIS & FAHP Liu \& Chen & FAHP Chang & FTOPSIS \\
\hline
\end{tabular}


- The objective of locating rescue and relief stations in the present study was to identify the first 5 options in locating the road rescue and relief station. The AHP and Liu and Chen FAHP methods identified these 5 options most confidently. Respectively, the FAHP Chang, TOPSIS, and FTOPSIS methods are most similar to the integration methods.

- When there is a large difference among options, all methods yield the same results. Thus, under such conditions, the method selection does not much affect the final result and it is necessary to simply choose the simplest method (the AHP and TOPSIS methods have the least amount of computation).

- When there is low difference among the options, the AHP, Liu and Chen FAHP, FAHP Chang, and even TOPSIS methods yield better results and using FTOPSIS is more risky.

- The Liu and Chen FAHP method has more accuracy, less complexity, and less volume of computation compared to the FAHP Chang method.

- Given Table 3, in the weighting of the criteria, if a nine-point-scale questionnaire is used instead of the pairwise comparison table, the nonfuzzy weighting methods will have similar results, and the simplest (row sum) method can be used instead of the conventional and complex Eigen vector method.

Among these methods, FTOPSIS exhibits the worst results, and is not recommended to be used in MCDM problems, especially when the values of the options are close to each other. In the present study, this method has the highest differences with other methods as well as with the final response of the integration strategies.

\section{Acknowledgments}

None

\section{Conflict of Interests}

Authors have no conflict of interests.

\section{References}

1. Mollaghasemi M, Pet-Edwards J. Making multiobjective decisions. Washington, DC: IEEE Computer Society Press; 1997.

2. Toloie-Eshlaghy A, Homayonfar M. MCDM methodologies and applications: A literature review from 1999 to 2009. Research Journal of International Studies 2011; 21: 86-137.
3. Vinodh S, Prasanna M, Hari Prakash N. Integrated fuzzy AHP $\square$ TOPSIS for selecting the best plastic recycling method: A case study. Appl Math Model 2014; 38(19): 4662-72.

4. Nguyen HT, Dawal SZM, Nukman Y, Aoyama H. A hybrid approach for fuzzy multi-attribute decision making in machine tool selection with consideration of the interactions of attributes. Expert Syst Appl 2014; 41(6): 3078-90.

5. Ghassemi SA, Danesh S. A hybrid fuzzy multicriteria decision making approach for desalination process selection. Desalination 2013; 313: 44-50.

6. Tavana M, Khalili-Damghani K, Abtahi AR. A hybrid fuzzy group decision support framework for advanced-technology prioritization at NASA. Expert Syst Appl 2013; 40(2): 480-91.

7. Sakthivel G, Ilangkumaran $M$, Nagarajan G, Shanmugam P. Selection of best biodiesel blend for IC engines: An integrated approach with FAHPTOPSIS and FAHP-VIKOR. International Journal of Oil, Gas and Coal Technology 2013; 6(5): 581-612.

8. Kasirian $\mathrm{MN}$, Yusuff RM. An integration of a hybrid modified TOPSIS with a PGP model for the supplier selection with interdependent criteria. Int $\mathbf{J}$ Prod Res 2013; 51(4): 1037-54.

9. Wu CM, Hsieh CL, Chang KL. A hybrid multiple criteria decision making model for supplier selection. Math Probl Eng 2013; 2013: 324283.

10. Kabak M, Burmaoglu S, Kazancoglu Yi. A fuzzy hybrid MCDM approach for professional selection. Expert Syst Appl 2012; 39(3): 3516-25.

11. Alcan $P$, Balin A, Basligil H. Fuzzy multicriteria selection among cogeneration systems: A real case application. Energy Build 2013; 67: 624-34.

12. Mahdavi A, Niknejad M. Site suitability evaluation for ecotourism using MCDM methods and GIS: Case study-Lorestan province, Iran. Journal of Biodiversity and Environmental Sciences 2014; 4(6): 425-37.

13. Wang F, Kang S, Du T, Li F, Qiu R. Determination of comprehensive quality index for tomato and its response to different irrigation treatments. Agric Water Manag 2011; 98(8): 1228-38.

14. Shelton J, Medina M. Integrated multiple-criteria decision-making method to prioritize transportation projects. Transportation Research Record Journal of the Transportation Research Board 2010; (2174): 51-7.

15. Rossetti MD, Selandari F. Multi-objective analysis of hospital delivery systems. Comput Ind Eng 2001; 41(3): 309-33.

16. Singpurwalla N, Forman E, Zalkind D. Promoting shared health care decision making using the analytic hierarchy process. Socioecon Plann Sci 1999; 33(4): 277-99. 
17. Vahidnia MH, Alesheikh AA, Alimohammadi A. Hospital site selection using fuzzy AHP and its derivatives. J Environ Manage 2009; 90(10): 3048-56.

18. Khaki AM, Mojaradi B, Ghobadipour B, Maghsoudi S, Naghibi F. Integration of GIS and analytical hierarchy process method for locating road emergency medical services station. Geosystem Engineering 2015; 18(2): 92-103.

19. Daskin MS, Stern EH. A hierarchical objective set covering model for emergency medical service vehicle deployment. Transport Sci 1981; 15(2): 137-52.

20. Doerner KF, Gutjahr WJ, Hartl RF, Karall M. Heuristic solution of an extended double-coverage ambulance location problem for Austria. Cent Eur J Oper Res 2005; 13(4): 325-40.

21. Saaty TL. The analytic hierarchy process: Planning, priority setting, resource allocation. New York, NY: McGraw-Hill; 1980.

22. Boroushaki S, Malczewski J. Implementing an extension of the analytical hierarchy process using ordered weighted averaging operators with fuzzy quantifiers in ArcGIS. Comput Geosci 2008; 34(4): 399-410.

23. Saaty TL. The analytic hierarchy process: Planning, priority setting, resource allocation. Pittsburgh, PA: RWS Publications; 1990.

24. Saaty TL, Tran LT. On the invalidity of fuzzifying numerical judgments in the Analytic Hierarchy Process. Math Comput Model 2007; 46(7): 962-75.

25. Zadeh LA. Fuzzy sets. Inf Control 1965; 8(3): 338-53.

26. Zadeh LA. Fuzzy sets as a basis for a theory of possibility. Fuzzy Sets Syst 1999; 100: 9-34.

27. Rahman MA, Rusteberg B, Gogu RC, Lobo Ferreira JP, Sauter M. A new spatial multi-criteria decision support tool for site selection for implementation of managed aquifer recharge. $\mathrm{J}$ Environ Manage 2012; 99: 61-75.

28. Van Laarhoven PJM, Pedrycz W. A fuzzy extension of Saaty's priority theory. Fuzzy Sets Syst 1983; 11(1): 229-41.

29. Chang DY. Applications of the extent analysis method on fuzzy AHP. Eur J Oper Res 1996; 95(3):
649-55.

30. Liu YC, Chen CS. A new approach for application of rock mass classification on rock slope stability assessment. Engineering Geology 2007; 89(1): 129-43.

31. Hwang CL, Yoon K. Multiple attribute decision making: Methods and applications a state-of-the-art survey. Berlin, Germany: Springer Berlin Heidelberg; 1981.

32. Saaty TL. How to make a decision: The analytic hierarchy process. Eur J Oper Res 1990; 48(1): 9-26.

33. Forman E, Peniwati K. Aggregating individual judgments and priorities with the analytic hierarchy process. European Journal of Operational Research 1998; 108(1): 165-9.

34. Bonacich P. Factoring and weighting approaches to status scores and clique identification. J Math Sociol 1972; 2(1): 113-20.

35. Hwang CL, Yoon K. Multiple attribute decision making: Methods and applications. Berlin, Germany: Springer-Verlag; 1981.

36. Ramik J, Korviny P. Inconsistency of pair-wise comparison matrix with fuzzy elements based on geometric mean. Fuzzy Set Syst 2010; 161(11): 1604-13.

37. Zhu K. Fuzzy analytic hierarchy process: Fallacy of the popular methods. Eur J Oper Res 2014; 236(1): 209-17.

38. National Highway Traffic Safety Administration. Fatality Analysis Reporting System (FARS) [Online]. [cited 2016]; Available from: URL: https://www.nhtsa.gov/research-data/fatalityanalysis-reporting-system-fars

39. Homer C, Huang C, Yang L, Wylie B, Coan M. Development of a 2001 National Land Cover Database for the United States. Photogram Eng Rem S 2004; 70(7): 829-40. 